\section{Relaciones de género en los intersticios de las prisiones argentinas. Tensiones en torno a derechos y cuidados}

Gender relations in argentine prisons intersticies. Tensions around rights and care

Ines Mancini

\section{RESUMEN}

Este trabajo se inscribe en un campo de investigación en formación respecto de los efectos extendidos del encarcelamiento. En particular, se propone complejizar los conocimientos respecto de las redes de afecto y cuidado construidas alrededor de las prisiones en la Argentina, específicamente de aquellas situadas en la provincia de Buenos Aires o pertenecientes al sistema federal (situadas en diversos puntos del país). Con este propósito, se utiliza una metodología cualitativa. La propuesta consiste en presentar un panorama que rescate las experiencias de las mujeres que desarrollan tareas de cuidado a varones detenidos. El artículo hace hincapié en la noción de género y evidencia una multiplicidad de formas de subordinación de estas mujeres. Para ello, se analizan las trayectorias de algunas mujeres con el propósito de dar cuenta de cómo muchas mujeres de los sectores populares son socializadas en este rol. En segundo lugar, se describen algunas de las labores que las mujeres llevan a cabo y se analizan las formas en las que ellas interpretan estas labores. En tercer lugar, se problematiza la visita íntima y la sexualización de los cuerpos en las visitas. En cuarto lugar, se describen las clasificaciones morales de las visitas. Por último, se analizan distintas formas de control a las que son sometidas las mujeres por parte de los detenidos. Todos los puntos analizados muestran que las mujeres realizan un trabajo esencial para la supervivencia de los varones detenidos. Además, dichos trabajos son llevados a cabo desde posiciones subordinadas, en la intersección de violencias institucionales y de género.

Palabras clave: efectos extendidos del encarcelamiento; género; cuerpo; cuidados; subordinación

\section{ABSTRACT}

This work is part of a research field regarding the extended effects of mass incarceration. In particular, its purpose is to broaden our understanding and knowledge regarding the networks of affection and care built around prisons in Argentina, specifically those located in the province of Buenos Aires or belonging to the federal system (located in various parts of the country). For this purpose, a qualitative methodology is used. The proposal consists of presenting a perspective that collects the experiences of women who carry out care tasks for detained men. The article emphasizes on the notion of gender and displays a range of ways of subordination of these women. For this, the course of action of some women are analyzed in order to account for how many women from the popular sectors are socialized in this role. Second, some of the tasks that women carry out are described and the ways in which they interpret these tasks are also analyzed. Third, it seeks to problematize the notion of intimate jail visit and the sexualization of bodies during visits. Fourth, the moral classifications of the visitors are described. Finally, different forms of control to which women are subjected by detainees are analyzed. All the points analyzed show that women perform essential work for the survival of male detainees. Furthermore, such work is carried out from subordinate positions, at the intersection of institutional and gender violence.

Keywords: extended effects of incarceration; gender; body; care; subordination
RELIGACIÓN

REVISTA DE CIENCIAS SOCIALES Y HUMANIDADES JOURNAL OF SOCIAL SCIENCES AND HUMANITIES REVISTA DE CENCIAS SOCIAIS E HUMANAS

INFORMACIÓN:

https://doi.org/10.46652/rgn.v6izo.856 ISSN $2477-9083$

Vol. 6 No. 30, 2021. e210856

Quito, Ecuador

Enviado: octubre 31, 2021

Aceptado: noviembre 27, 2021

Publicado: diciembre 12, 2021

Publicación Continua

Sección Dossier | Peer Reviewed

\section{AUTORA:}

(D) Ines Mancini

Universidad Nacional de San Martín Argentina

inesmmancini@gmail.com

\section{Conflicto de intereses}

La autora declara que no existe conflicto de interés posible.

Financiamiento

No existió asistencia financiera de partes externas al presente artículo.

Agradecimiento

N/A

Nota

El artículo no se desprende de un trabajo anterior.

ENTIDAD EDITORA

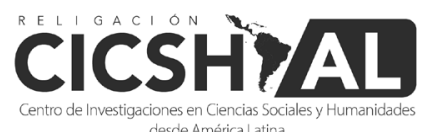




\section{Introducción: jerarquías de género y formas de invisibilidad}

El crecimiento de las tasas de encarcelamiento en America Latina en general y en Argentina en particular tiene consecuencias diversas. En este trabajo, se referirá específicamente a los efectos que el encarcelamiento tiene para los afectos de los detenidos, en particular para las mujeres. Merced a este crecimiento del encarcelamiento y la selectividad del sistema penal, la experiencia de acompañar a un detenido alcanza a un parte significativa de las mujeres de los sectores populares. El trabajo de campo aquí presentado se circunscribe fundamentalmente a mujeres que residen en barrios populares en la ciudad o en la provincia de Buenos Aires y acompañan a detenidos en el sistema penitenciario federal, con penales ubicados en la ciudad o en puntos distantes del país o a detenidos en las cárceles de la provincia de Buenos Aires. Si bien las realidades de cada penal son diferentes, los detenidos circulan a lo largo del tiempo por distintos penales y muchas mujeres asisten a más de un detenido. Así cuando los presos circulan por distintos penales, las familiares también lo hacen. Si bien cada penal y su entorno presentan particularidades existen puntos en común que permiten que este trabajo pueda ser puesto en diálogo con otros trabajos como el de Ferreccio (2017) en la provincia de Santa Fe.

En este sentido, este trabajo coincide con la importancia de analizar a un actor fundamental en el universo carcelario argentino que, aunque ha sido poco considerado por la literatura y por los actores institucionales, constituye un pilar de la supervivencia del sistema y de los detenidos: los familiares. Como señalan todos los estudios, los familiares son generalmente mujeres (Ferreccio, 2017). En este sentido, es preciso analizar las redes de afectos que circundan las prisiones, pues ignorarlas implicaría dejar a un lado parte de la articulación política que produce a estas mismas instituciones (Corazza Padovani, 2015).

Ahora bien, nos interesa dar cuenta de estas redes de afecto teniendo en cuenta las jerarquías de género implicadas en ellas. Y ello es así porque las mujeres están envueltas en múltiples opresiones yuxtapuestas. Pensar en las jerarquías de género y los mundos carcelarios implica trabajar en un solapamiento de invisibilidades: la invisibilidad de las labores y desigualdades femeninas se superpone con la opacidad de los sufrimientos del encarcelamiento (Sykes, 2017).

En efecto, los primeros aportes a las teorías feministas en el Siglo XIX discuten alrededor de lo público y lo privado y la inhabilitación de la mujer en la esfera pública (Vázquez Laba, 2019). Si como señala Delphy (2013), el trabajo doméstico constituye una extorsión directa del cónyuge, la situación que se da en las cárceles en las que las mujeres han de realizar una serie de tareas (cocinar, comprar elementos y transportarlos) para que los varones detenidos puedan reproducir sus vidas merece una observación particular. ¿cómo es que esta extorsión continúa operando cuando las mujeres son también quienes quedan en general a cargo del rol productivo? ¿cómo se lleva a cabo este trabajo doméstico y cómo se reproducen las jerarquías de género pese a los límites impuestos por la prisión? 
Dada la selectividad del sistema penal, la mayoría de los detenidos son varones, jóvenes y pobres. Y las mujeres que los asisten son del mismo sector social. En este sentido, proponemos recuperar la noción de interseccionalidad (Stolke, 2014) para dar cuenta la de la interacción de desigualdades que atraviesan estas mujeres.

En este trabajo, se analizarán las experiencias de un conjunto de mujeres que se desenvuelven en los intersticios de los penales y que resultan fundamentales para el funcionamiento y la existencia de los mismos. En efecto, hay un actor en el universo de relaciones del sistema carcelario que es el familiar. El familiar es que posibilita que el preso coma, que tenga ropa, elementos de higiene, visitas, atención médica, traslados cuando peligra la vida. Y el familiar es una mujer. La propuesta de este articulo es mostrar y problematizar estos trabajos, así como también evidenciar los procesos de producción y reproducción de formas de subordinación de las mujeres.

\section{Metodología de trabajo}

El trabajo de campo comenzó en 2014 y ha atravesado diferentes instancias. Se trata de una metodología cualitativa centrada fundamentalmente en la etnografía. Siguiendo la propuesta de Marcus (2001), se llevó a cabo una etnografía multisituada que implica seguir a las personas por distintos ámbitos. Así, nuestra preocupación por los efectos extendidos del encarcelamiento implicó seguir a las mujeres que atienden las necesidades y demandas de los detenidos, sosteniendo una relación permanente con la prisión, más allá de sus límites.

La principal organización en la que se realizó observación participante es la Asociación de Familiares de detenidos (ACIFAD), extendiendo este trabajo a los distintos recorridos de algunas mujeres de la asociación comprometidas con la militancia por los derechos vinculados a los detenidos y sus familias. El seguimiento implicó tanto acompañar a algunas mujeres en distintos momentos de su vida cotidiana, como la participación de reuniones formales de la Asociación con organismos del Estado y de la sociedad civil. También, incluyó la participación en manifestaciones y celebraciones personales y colectivas. Adicionalmente, seleccionamos mujeres que participan con frecuencia de las reuniones de la Asociación para realizar entrevistas en profundidad. A lo largo del artículo, luego de cada dato citado, se aclara si proviene de la observación (registro de campo) o de una entrevista formal.

La Asociación cuenta con algunas familiares que asisten a la reuniones todas las semanas y contribuyen con la difusión de las actividades y reclutamiento de nuevos miembros, mientras que al mismo tiempo algunas personas acuden a resolver problemas específicos. También asisten regularmente profesionales (abogados, psicólogos, sociólogos y antropólogos) que colaboran con las labores de acompañamiento a los familiares.

Más allá del registro de las reuniones de discusión que tienen lugar en la asociación, se detuvo la atención también en las conversaciones, aparentemente más triviales, con las mujeres en 
medios de transporte o mientras preparaban el mate para alguna reunión. Allí, gracias a las conversaciones distendidas y jocosas pude problematizar algunas de las incomodidades respecto al rol de cuidado que ejercen.

Por otro lado, se realizó un seguimiento sistemático de personas e instituciones en redes sociales. La retroalimentación entre las relaciones virtuales y cara a cara ha sido provechosa para conocer algunos aspectos de las vidas de las mujeres que podrían permanecer ocultos en una entrevista formal tradicional.

Desde comienzos de 2020, se participó de reuniones semanales virtuales con mujeres familiares de detenidos, merced a las medidas de aislamiento producto de la pandemia. A partir de entonces, comenzaron a intervenir nuevas familiares (algunas que no podían concurrir a las reuniones en el centro de la ciudad), mientras que otras de las asistentes regulares tuvieron problemas para sostener la conexión virtual con estabilidad.

Es preciso destacar que todas estas instancias de construcción de datos se retroalimentan entre sí. En este sentido, las conversaciones informales permitieron obtener los contactos para acceder a las redes sociales de las familiares, al mismo tiempo que aquello que fue leído en redes sociales pudo ser retomado para ser repreguntado en entrevistas formales con familiares.

Siguiendo a Sciortino (2012), la etnografía tiene una enorme potencia para dar cuenta de una perspectiva de género que analice situaciones atravesadas por las mujeres, dando cuenta de la intersección del género con otras categorías sociales, como a clase o la generación.

\section{Trayectorias: cárcel y cuidados}

Al comenzar el trabajo de campo, fueron notorias algunas similitudes y divergencias entre las mujeres que asistían regularmente a la Asociación de Familiares, pero entre ellas una característica saliente que las unificaba: trayectorias compartidas de haber asistido a distintos penales para acompañar (seguir) a distintos familiares. Algunas comenzaron desde pequeñas visitando a sus padres o tíos, luego visitaron cónyuges o hermanos y más tarde hijos. Incluso, muchas de ellas tienen más de un familiar o más de un hijo preso por el que se debe velar.

Como sostiene Ferreccio (2017), la detención de alguien de la familia es vivida en plural. Y cuando se piensa en las detenciones que tienen lugar en los barrios populares, es de señalar que las detenciones y el procesamiento penal no resultan sorpresivas. Así - como señala la autora - los modos de actuar remiten a trayectorias familiares. Incluso, este destino pensado como ineludible es señalado explícitamente como preferible a su alternativa: el cementerio.

Entonces, el trabajo de campo muestra la disponibilidad de estas mujeres para visitar penales (y la realización de trabajos vinculados a esto, sobre la que nos detendremos más adelante) que es relatada como un hecho natural de las vidas. Incluso, quienes por razones de distancia no acuden frecuentemente a la cárcel relatan sus vidas involucradas con el devenir del mundo carcelario, ya que más allá de la visita realizan trámites, pagan abogados, compran bienes para enviar o sostienen vinculaciones telefónicas. 
Como sostienen Faur y Pereyra (2018), el cuidado es requerido por todos para sobrevivir, aunque se requieren distintas intensidades en diversos momentos de la vida. Pese a que sea una necesidad compartida, los provisión del cuidado no se reparte equitativamente, sino que históricamente las mujeres han sido las principales encargadas de estas labores.

Ahora bien, ello no implica hablar de tendencias naturales o instintos, sino que, "La asignación de las responsabilidades del cuidado refleja antes bien las pautas culturales de una sociedad, plasmadas mediante la definición de sistemas de derechos y responsabilidades atribuidos a los hombres y mujeres por parte de los regímenes de bienestar” (Faur y Pereyra, 2018, p. 495).

Entonces, la organización social del cuidado se vincula estrechamente con desigualdades entre los géneros y las clases sociales. Pensar en los modos de organización de los cuidados en las cárceles implica profundizar, a partir de un contexto específico, en los modos en los que las desigualdades se producen y reproducen a partir de la distribución del cuidado. Como se señaló, este trabajo se realizó con mujeres residentes en la ciudad o provincia de Buenos Aires (Argentina). Ahora bien, entendemos que estos hallazgos pueden dialogar con investigaciones realizadas en otras latitudes.

Posar la mirada sobre estas desigualdades supone el esfuerzo de desmontar algunos procesos naturalizados e invisibilizados por los propios actores sociales con los que se interactuó en esta investigación. Aunque también se han observado algunos procesos de problematización de estos trabajos de cuidado y las posibilidades de establecer diálogos y resonancias con los planteos feministas.

Como se señaló anteriormente, la socialización de las mujeres de sectores populares en este rol de acompañar, visitar y asistir a un detenido desde edades tempranas lleva a naturalizar la disponibilidad para realizar estas tareas, reforzando los roles femeninos de cuidadoras.

\subsection{La verdad de la milanesa: Seguir a un preso es un trabajo}

Cuando se piensa en las relaciones de cuidado, se suele establecer una automática relación con el amor, invisibilizando aquello que hay de obligación en las relaciones con los seres queridos. El cuidado se trata de un trabajo que se da por descontado, pese a que puede suponer múltiples malestares.

Así, mientras los varones detenidos están impedidos de circular, miles de mujeres atraviesan largas distancias para visitarlos. Incluso, hay mujeres que se han mudado de localidad para estar más cerca del penal, reorganizando sus propias vidas en función del mundo carcelario.

A las visitas se acude con mercaderías demandadas por los detenidos. El bulto cargado con mercadería recibe el nombre de "bagayo". Un bagayo contiene una sumatoria de trabajos realizados, generalmente, por mujeres: trabajos con los que se consiguió plata para comprar cosas, elementos de limpieza e higiene personal, mercadería para preparar comidas, y comidas preparadas y gaseosas. 
En las reuniones en la asociación de familiares suelen hacerse chistes entre mujeres porque alguna de ellas compraba las milanesas hechas en una carnicería, en lugar de empanar cada trozo de carne. Incluso, una vez una mujer comentó que cuando su marido salió de la cárcel le pidió que le presente al carnicero porque “es el hombre que me dio de comer 14 años". (Registro de campo, pareja de un detenido, 20 de septiembre de 2018).

Sin embargo, al indagar en esos comentarios jocosos, quienes "no hacían" las milanesas y eran consideradas cómodas por comprarlas ya elaboradas, comentaban con naturalidad que el día de la visita se levantaban a las 4 de la mañana para freír esas milanesas y que llegaran "un poco calentitas" al momento de la visita.

Cabe recordar que se trata de mujeres que pertenecen mayoritariamente a los sectores de menos recursos de la población. En este sentido, la compra de bienes deseados por los detenidos como las gaseosas o las milanesas son en desmedro de las propias necesidades o deseos o de los deseos de otros miembros de la familia. En ocasiones, las reuniones en la asociación de familiares se convierten en un espacio en el que se habilita la posibilidad de expresar estos malestares al mismo tiempo que se puede señalar que "no me arrepiento de seguirlo como lo estoy siguiendo" (Dora, marido preso, 15 de abril 2021).

Así, como se escuchan menciones a cuestionamientos -aunque generalmente incipientes - a estos roles, también las mujeres familiares muchas veces atribuyen al afecto la capacidad de salvar al detenido. $Y$ en este punto, el amor se liga definitivamente a una obligación moral.

Estela habló de lo bien que está Alejo: es un caballero y no se le nota que estuvo toda una vida preso. Dice que eso es por el amor de Andrea. (Registro de campo, 14 de julio de 2015).

\section{Sexo y sexualidades en las visitas}

Las visitas a la cárcel pueden implicar una visita regular o "la íntima". La íntima es un tipo de visita habilitada por el servicio penitenciario para parejas establecidas e implica que el detenido y su pareja pueden pasar tiempo a solas en un espacio privado, en el que se supone tendrán relaciones sexuales. Esto no quiere decir que sea la única instancia en la que es posible tener relaciones sexuales.

Ahora bien, el cuerpo de la visita es un cuerpo sexualizado se trate o no de una visita íntima. Esta sexualización de los cuerpos cobra su máxima expresión en la requisa, el acto de revisar a los ingresantes para impedir la introducción de elementos prohibidos. En este sentido, se han registrado tanto quejas explícitas como "nos sentimos violadas sin ser violadas" como chistes respecto del tipo de requisas vividas, tal como "menos mal que me depilé".

Como señala Godoi (2016), la intimidad de los cuerpos en este contexto puede ser pensada como un espacio estratégico de actualización de las técnicas de gobierno. La requisa implica una serie de controles que apuntan a evitar el ingreso de elementos prohibidos. Ahora bien, dichos controles son moralizantes: la vestimenta debe obedecer a ciertas reglas que no son 
necesariamente conocidas por las visitas. La contingencia de estas reglas y su aplicación se observa en que las mismas vestimentas que un día son aprobadas pueden ser desaprobadas en otra oportunidad. En ocasiones, cuando una ropa es desaprobada, se le pide al preso que "baje" una ropa, entonces la mujer entra vestida con ropa del varón.

Es interesante detenerse en la arbitrariedad y en la imposibilidad de anticiparse al conocimiento de estas normas de vestimenta, puesto que allí se genera una mirada que moraliza a las mujeres que deben evitar lucir provocativas, así como también se refuerza su posición subordinada y sujeta a la mirada del servicio penitenciario. Sin embargo, estas miradas moralizantes conviven también con el deseo de resultar atractiva para la pareja o para otros puesto que las visitas constituyen un espacio de sociabilidad para los sectores populares.

La arbitrariedad del poder del servicio penitenciario atañe tanto a las ropas y bienes que pueden o no ser ingresados como también al tipo de requisa que se realiza. No está estipulado qué está permitido hacer para el servicio penitenciario. $Y$ una requisa que se prolonga se justifica en la clasificación de sospechosa de la visita. Godoi (2016) sigue los planteos de Das para señalar que el cuerpo femenino puede ser pensado como territorio en disputa por varones en guerra. Así, tanto la posesión, aniquilación, protección o recuperación del cuerpo femenino pueden pensarse como parte de esa figuración, en donde el cuerpo femenino es un elemento central de las relaciones belicosas entre varones, y en este sentido, se propone inscribir esa mirada que del mismo hace el servicio penitenciario.

En efecto, la requisa objetiva privilegiadamente los cuerpos de las visitas en sus dimensiones sexuales. $Y$ esto constituye al mismo tiempo una forma de sexualización y de feminización, en tanto se trata de cuerpos que son sometidos a un escrutinio viril y fragilizados por una fuerza inconmensurable. Entonces, la prisión generiza cuerpos. (Godoi, 2016). Se trata de un ejercicio de poder y vigilancia ejercido sobre cuerpos que no están legalmente castigados.

Ahora bien, el ejercicio legal de la sexualidad de las parejas cuando uno de los dos se encuentra privado de su libertad fue reconocido legalmente en 1996 y que puede ser interpretado como un derecho al que acceden los detenidos. El ejercicio de dicho derecho ha producido consecuencias en las vinculaciones dentro y fuera de las cárceles (Oleastro, 2019).

Sin embargo, se trata de un derecho complejo porque puede implicar una obligación para las parejas.

\footnotetext{
Estelita cuenta de su marido en Caseros. La llamaba la trabajadora social para que fuera a tener relaciones "Decile que yo no voy a ir a garchar a la cárcel" El decía que yo tenía un macho afuera y yo estaba con los chicos, tratando de sobrevivir. Caseros es lo peor, y yo conozco todas las cárceles. En la cárcel no me caliento, me da frío en el alma y en el cuerpo (Registro de campo, pareja y madre de detenidos, 20 de junio de 2017).
}

Entonces, el ejercicio del derecho a la sexualidad de los varones detenidos puede suponer también una profundización de la sujeción de algunas mujeres que terminan convocadas por 
el mismo estado a tener relaciones sexuales para potenciar el bienestar del detenido. Así, los cuerpos de las mujeres familiares son cuerpos fragilizados y sexualizados por la violencia institucional.

\section{No somos todas iguales: categorías morales en las visitas}

Como ya mencionamos, las visitas que recorren grandes distancias y quienes siguen a los varones detenidos son en su mayoría mujeres. Sin embargo, en este universo del encarcelamiento extendido existe un preciso sistema de clasificación que adjudica y jerarquiza en términos morales a las mujeres. En efecto, ellas pueden compartir la fila, pero no son todas iguales. Estas diferencias están fundadas en la relación que se tiene con el detenido, pero también en las motivaciones para asistir a la cárcel, así como también los modos de comportarse en relación a las demás mujeres.

En primer lugar, se encuentran las madres, quienes gozan del mayor prestigio, pero también de la mayor responsabilidad y carga de trabajo en las tareas de cuidado. Las madres reconocen para sí mismas una categoría moral superior: ellas van a estar siempre, se encargan por amor y no por interés.

Adicionalmente, las madres de los detenidos toman también a su cargo la responsabilidad total o parcial del cuidado de los hijos del detenido. Además, estas relaciones de cuidado de los hijos de un detenido no implican atender exclusivamente a las necesidades económicas de los niños, sino que también suele implicar tomar a su cargo la vinculación de los hijos con el detenido cuando este no está en pareja con la madre de los niños. Como se analizó anteriormente (Mancini, 2019, 2020), las madres se perciben responsables por el delito, por el bienestar en la cárcel, por el futuro.

En el 2010 mi papá tuvo su acv y a mi la casa se me desbandó. Mi hijo con las drogas. (...) Gratuitamente me la tengo que aguantar porque vivo en ese lugar y porque no tengo plata para pagar un abogado. Me siento atada porque no sé qué puedo hacer. Yo no tengo la inteligencia para hacerme cargo de todo (Entrevista con madre de detenido, julio de 2018).

En este esquema de jerarquizaciones, luego de las madres se ubican las parejas de los detenidos, pero no todas las parejas ocupan la misma jerarquía ni se vinculan de la misma manera con los otros integrantes de las redes de cuidado de los presos.

Dentro de las parejas, quienes son más reconocidas son aquellas que se vinculan con las madres de los detenidos y se distribuyen las tareas. Las parejas de los presos en ocasiones son habilitadas por las madres. Y en estos casos, hay una división del trabajo: por ejemplo, una madre que se encarga de los tribunales y de los gastos de armar el bagayo y los viajes pero la que realiza la visita es la novia. Estas mujeres son valoradas por las madres de los detenidos, más allá 
del modo en el que se hubiera desarrollado la relación en los tiempos previos a la detención. Permanecer cuidando a un detenido y encargarse de sus asuntos es visto como una verdadera muestra de amor:

Cuando cayó preso, la única que estuvo fue ella, mi nuera. Ahí se dieron cuenta de que estaban enamorados (Registro de campo, madre de un detenido, 3 de junio de 2019).

Aunque también es cierto que muchas veces, se refieren situaciones de sujeción, en donde la nuera es dominada por la suegra para cumplir con ciertas tareas. Asimismo, estas relaciones de cooperación pueden ser atravesadas por tensiones:

Porque las chicas de hoy tienen hijos, pero no trabajan (Madre de detenido).

A mi hijo le gustan las chicas lindas y cómo no va a ser linda si se levanta a las 12 (Madre de detenido) (Registro de campo, 7 de septiembre de 2018)

Como señala Jelin (2012), hay una complejidad en las relaciones de cuidado implicadas en los cruces generacionales y de género que es preciso estudiar. Las tensiones en las relaciones entre suegra y nuera pueden resultan difíciles de asir en una relación, pero hacen parte de estas dificultades.

Como se señaló anteriormente, no todas las parejas tienen el mismo nivel de prestigio: una cosa es una mujer que estaba en pareja cuando el varón quedó detenido y otra categoría reviste aquella mujer que conoce a su pareja en la cárcel.

Yo fui a la cárcel fui por amor, porque estaba enamorada de esa persona. No soy de esas que andan de penal en penal (Registro de campo, 21 de octubre de 2018).

Ir "de penal en penal” alude a una práctica de algunas mujeres de los sectores populares que acuden a las visitas a acompañar a una amiga que tiene que visitar a alguien o bien que visitan amigos. Estas prácticas hacen suponer que las visitas a los penales constituyen un espacio de sociabilidad importante de los sectores populares.

En el escalafón más bajo de esta jerarquía están las ranas. Son esas mujeres que van a la cárcel a ver a varones que están en pareja. Las ranas, también denominadas réplicas, son mujeres en muchas ocasiones de más edad que el detenido que visitan y también en ocasiones son señaladas como quienes llevan drogas y tiene relaciones sexuales con los detenidos. También, desde la perspectiva de las otras mujeres, son referidas como las que ocasionan los problemas en las visitas.

Ahora bien, este esquema de etiquetas y jerarquías es reconocido por todos los actores habitan estos espacios y los juicios morales son activados situacionalmente produciendo distintos efectos. Así como desde la perspectiva de las mujeres que son parejas establecidas de un 
detenido se genera un juicio moral hacia quienes "lo toman como un hobbie ir a la cárcel, como una excursión" y "van de penal en penal”, ellas son también agredidas por rumores respecto de las "otras visitas" que reciben sus parejas. Chistes, rumores que señalan "la otra vez vino tu réplica” producen celos, enojos y peleas, generalmente entre mujeres. Estos rumores respecto de la posibilidad de que el marido o pareja sea visitado por otra mujer son enunciados por otras mujeres en la fila o bien por el servicio penitenciario.

Haciendo la fila te dicen: tu esposo ya tiene una mujer, tiene que dar de baja a la primera y todas se reían (Registro de campo, 14 de abril de 2016, Pareja de detenido).

Durante 2020, la reanudación de las visitas después de la interrupción en el marco de las medidas de aislamiento por la pandemia, implicaron un control más estricto respecto de quienes estaban habilitados a ir a la visita que produjo cierto alivio en algunas mujeres. Una mujer contó que en una discusión le dijo a su pareja: "tu réplica no va a entrar nunca más: solo madre y concubina".

\subsection{Paradojas: continuidades de los controles y libertades}

La utilización y activación de estas categorías que posicionan a las mujeres en distintos lugares respecto del varón detenido, son empleadas por todos los actores involucrados: las madres se refieren a las novias o relaciones de sus hijos evaluándolas de acuerdo al rol que cumplan en los cuidados, las parejas formales, se refieren despectivamente a las ranas, pero son objeto de burla de otras mujeres (otras visitas o personal penitenciario) cuando su pareja es visitado por otra mujer.

Asimismo, la clasificación burocrática de las relaciones que habilitan las visitas no siempre se corresponde con la dinámica de las relaciones amorosas. En efecto, hay varios casos de ex parejas que siguen figurando en los registros del servicio como esposas o concubinas pues concurren a la visita con los hijos del detenido; en esos casos las parejas actuales deben ingresar como "amigas" del detenido.

Además, los varones detenidos también suelen activar estas clasificaciones y los celos en función de sus intereses y sentimientos. Así, una joven contaba que su novio le decía: "me voy a conseguir otra piba, que venga, que me traiga". En estas relaciones en las que solo las visitas pueden aportar bienes materiales, los mismos tienen tal vez un nivel de explicitación mayor que en otras relaciones afectivas.

Una de las maneras en las que las mujeres se sienten compelidas a acercar estos bienes tiene que ver con el sentimiento de culpa que atraviesa la vinculaciones de las relaciones entre madre e hijo como mostramos anteriormente (Mancini, 2020) pero que se extiende a otras relaciones de pareja o amistad.

En este sentido, existe un acuerdo generalizado entre las mujeres acerca de que "ellos son re demandantes”. Incluso, esa demanda parece ir más allá de la voluntad del propio varón detenido: 
El valora, no es exigente. me dice, vení cuando puedas, yo te voy a esperar acá. y después me dijo traeme esto, esto, esto y esto (Entrevista con pareja de un detenido, 14 de abril de 2018).

En este sentido, el trabajo de la Asociación consiste en producir un acompañamiento a los familiares, pero también la producción del extrañamiento respecto de ciertos niveles de demanda. Pues, existe la idea de que

Te hacen sentir culpable, que vos estás libre y podés hacer de todo. Entonces, te hacen pedidos desmedidos (Registro de campo, madre de detenido, 20 de mayo de 2017).

En este sentido, las reuniones colectivas en la asociación de familiares tienden a poner en discusión y perspectiva estos sentimientos de culpa y reflexionar sobre el alcance de la ayuda y la importancia de cuestionar la aceptación del sacrificio por parte de muchas mujeres.

Hacer lo posible. No es sacrificio. Es lo que puedo porque tengo ganas. Lo posible es lo que me voy a sentir bien de poder dar, acompañar es juntos, no que hagas todo vos (Registro de campo, una profesional en la Asociación de familiares, 20 de mayo de 2017).

Ahora bien, para muchas mujeres resulta difícil señalar que el acto de seguir a un preso constituye una elección. La obligación moral tiene un peso decisivo en la permanencia de muchas mujeres realizando estas labores a lo largo de años.

Así como también cuesta reconocer que esta idea de que la visita es sagrada responde a la perspectiva del preso pero no necesariamente a la de las familias. En efecto, el tiempo de visita siempre será insuficiente para el detenido pero implica una movilidad y una disponibilidad de tiempo para las mujeres que merece ser considerada. Así, cuando una joven se quejaba de que su novio detenido en una cárcel federal había sido trasladado a la provincia de Neuquén tras la condena, otras compañeras le respondían entre risas: “descansás de ir a Devoto!” (Cárcel en la ciudad de Buenos Aires).

Megan Comfort (2008, 2011) analiza las visitas a una prisión en Estados Unidos. Allí encuentra que para las mujeres que visitan los penales rige una versión debilitada pero forzosa de las regulaciones que rigen las vidas de los prisioneros. En este sentido, durante la visita, las mujeres son sometidas a la espera, al control a partir de unas reglas arbitrarias y cambiantes y a una pérdida de su autonomía. De modo que ellas también padecen los dolores de la reclusión (Sykes, 2017) y por ello la autora entiende que sufren una prisionización secundaria que define y transforma la identidad personal y pública de estas mujeres.

Entendemos que este alcance del padecimiento se extiende más allá de los momentos específicos de la visita, y que como afirma la autora muchas vidas se reorganizan en función del compañero detenido. 
También es cierto que para algunas mujeres ello implica la posibilidad de vivir una vida más libre. En tanto y cuanto se ven liberadas de la presencia cotidiana del compañero. Pero este incremento de las libertades implicado para algunas mujeres, es la fuente de un intento de control desde adentro por parte del preso. y esto, para algunas, mujeres resulta sumamente opresivo.

En una entrevista con un varón mayor que pasó buena parte de su vida detenido, contó que él veía a los presos más jóvenes sufrir por la imposibilidad de controlar a sus novias. Desde su perspectiva, todos son objeto de burla por otros internos que realizan permanentes bromas sobre la posibilidad de que sus novias tengan encuentros con otros varones mientras ellos están detenidos. Estas sospechas se mezclan con chismes y diversos tráficos de información que atraviesan prisiones y llegan a los barrios (Barbosa, 2006; Telles, 2011; Corazza Padovani, 2015). En este sentido, trabajos como el de Corazza Padovani (2015) en Brasil muestran que estas redes de afecto que participan en la construcción de las cárceles también implican la circulación de información y chismes respecto de las relaciones amorosas, dando cuenta de que relaciones que tienen lugar en cárceles de mujeres son sabidas en cárceles de varones.

Así sucede que muchas mujeres sienten que el teléfono celular constituye tanto un elemento que facilita la interacción cotidiana con sus seres queridos, así como también un instrumento de control. En efecto, hay casos en los que las mujeres relatan que si no atienden rápidamente el teléfono se transforman de inmediato en objeto de sospecha para sus parejas, por ejemplo:

Terminé en la salita descompuesta. Me medicaron. Me hicieron análisis porque tengo temblores. (llora). No me deja dormir. Me llama a cada rato. No llevo el celular y tengo que hacer todo rápido por si me llama. No puedo usar mi cabeza (Registro de campo, pareja de un detenido, 20 de noviembre de 2020).

De este modo, la cárcel no implica un límite al control que algunos varones ejercen sobre las mujeres, como tampoco a las amenazas o distintas violencias de género. Ahora bien, los celos no circulan en una sola dirección, sino que los detenidos también utilizan los celos y las amenazas de conseguir a otra mujer como modo de amedrentar e impulsar a sus parejas a que asistan a todas las visitas o les consigan determinados bienes. Según han relatado algunas mujeres, en situaciones de conflicto han sido amenazadas por sus compañeros detenidos con ponerse en contacto - fundamentalmente a través de redes sociales - con otras mujeres:

Mira esta que me llamó nueva, mira esta que me mandó la soli.

Una vez me dijo: ay comí re cheto, porque fue una vieja. A Kevin en 6 años le cargué crédito 30 veces. No sé quién le carga. El fuma y yo nunca le llevé cigarros (Registro de campo, pareja de detenido, 15 de agosto de 2020).

Sin embargo, estas mujeres dirigen sus críticas a las ranas y no hacia los varones que promueven estas relaciones. Así, las ranas son objeto de críticas por parte de las mujeres que forman parejas estables con varones detenidos. 
En vez de buscar algo afuera, ella en Instagram o Facebook o Badoo. No les importa, arruinaron familias. El preso a la señora le dice te quiero ver, te extraño. A veces el preso elige hablar más con la rana. Las boludas son ellas que se prestan al juego. Si encima a los presos ni se les para porque están muy drogados (Entrevista con pareja de un detenido, 27 de agosto de 2020).

Como puede apreciarse, la mayoría de las mujeres que entrevistamos toleran o al menos comprenden los controles obsesivos de los que son objeto al mismo tiempo que disculpan las infidelidades de los detenidos y, en todo caso, reprochan a otras mujeres por prestarse a ese juego.

\section{Feminismos, punitivismos, adentro y afuera}

Desde el comienzo de este trabajo de campo, llamó la atención que las mujeres participantes de las reuniones se mostraran críticas con el feminismo. Por lo general, planteaban que había una cierta "inflación" en el reconocimiento de los derechos de las mujeres. En más de una oportunidad, señalaron que "decís violencia de género y ya está”, como si los varones que ellas asistían fueran víctimas de los derechos de las mujeres. Aunque solo se registraron dos casos de familiares que asistían a un varón condenado por femicidio, ocurrió en otras instancias que las libertades anticipadas fueran revocadas por episodios que, desde la perspectiva de las informantes, eran confusos pero que habían sido clasificados como violencia de género.

En un sentido similar, varias mujeres reclaman que las feministas no las reconocían, que ellas también son mujeres y que el feminismo debería velar también por sus derechos. En este sentido, los discursos ligados a los derechos de las mujeres resultaban sospechosos. En efecto, luego de haber asistido a una manifestación de "Ni una menos" en la que me hubiera encontrado con un trabajador social que asistía a algunas reuniones de la asociación, debí darle explicaciones a algunas de mis interlocutoras que se mostraron extrañadas cuando este trabajador social contó que nos habíamos encontrado en la marcha de las mujeres. En otras ocasiones, discutí con algunas mujeres si la reivindicación de “Ni una menos” implicaba o no pedir más cárcel para los varones. También he presenciado discusiones a raíz de que alguien conociera en visitas a la cárcel a femicidas de casos que habían tomado público conocimiento. En esos casos, fui observada por haber señalado que eran asesinos y se me recordó que quien los había condenado era la misma justicia a la que en tantos otros casos podíamos poner en duda.

Sin embargo, a lo largo de los años, el crecimiento de los movimientos feministas en la Argentina, así como el crecimiento de la asociación y la participación en ella de una diversidad de compañeras, abrió la posibilidad de transformaciones y fisuras en esta supuesta oposición entre feminismos y derechos de los detenidos.

Sin lugar a dudas, un hito de esta transformación de la asociación se dio cuando una psicóloga que colabora en ella propuso hacer un taller de género donde las mujeres pudieran charlar algunos temas que podían implicar pensarse más allá de su condición de familiares, más allá 
de la cárcel. La conformación de este taller se dio como coronación de algunos cambios en las intervenciones en las reuniones en donde el consejo que se le daba a las mujeres era que no siempre la mejor respuesta consistía en sacrificar todo, donde algunas mujeres podían permitirse señalar que no siempre tenían ganas de ir a la visita, o algunas podían señalar que en ciertos momentos no iban.

Cuando la psicóloga invitó a algunas mujeres a formar parte del taller de género, algunas de estas familiares que asisten con regularidad a las reuniones y que han acompañado esta evolución en el pensamiento se mostraron entusiasmadas enseguida, mientras que para otras el hecho constituyó una sorpresa, asociaban la idea de un taller de género pura y exclusivamente con la violencia y sentían que asistir constituía en si mismo un acto de denuncia a sus parejas. "Yo puedo ir pero mi pareja no es violento" (Registro de campo, 4 de junio de 2019). Después cuenta que ella se sacó una foto con un amigo y el tipo no le habló por dos días. Para mí sorpresa, me enteré unos días después de que su novio es un conocido y condenado femicida.

Así como resulta difícil para muchas mujeres familiares reconocerse como sujetas de derechos y pensar que los reclamos colectivos de los feminismos pueden contemplar algunas de sus opresiones, también es cierto que, para muchos militantes ligados a los derechos de las personas detenidas, resulta difícil ver que la promoción de muchos derechos de los detenidos implica necesariamente obligaciones para otras personas, usualmente mujeres. Esto sucede, por ejemplo, con el ya mencionado derecho a la visita íntima como también al derecho a la prisión domiciliaria en los casos en los que corresponde.

En particular, es preciso estudiar las consecuencias de los arrestos domiciliarios no solo para las personas detenidas, sino también para quienes están involucrados en sus consecuencias cotidianas. En una oportunidad, Lorena, una antigua participante de las reuniones da ACIFAD, se contacto a un reunión virtual que tuvo lugar durante el 2020. Allí nos presentó a su vecina Juana. Ella contó que su marido tiene arresto domiciliario. Juana tiene más de 40 años y cuatro hijos. Antes de la salida de su marido, Juana compartía la casa con algunos de sus hijos, pero para que este saliera, ella comenzó a alquilar una casa en el mismo barrio, que solo habitan ella y su marido.

Desde el momento en el que se presentó, Juana contó que tiene muchos problemas con su marido porque "a mí me gusta salir, ir a la casa de mis hermanos, ir tomando mate". Aparentemente, su marido quería que ella estuviera en la casa con él y que saliera exclusivamente a comprar la comida. Juana contaba con asombro que él no la trataba bien y se culpaba a sí misma por haber cometido el error de casarse, dando por descontado que se trataba de una situación irreversible.

Yo lo conocí adentro. Esto me pasó por calentona, ¿a mí quién me mandó a casarme? Dos teléfonos me dieron, y se me ocurrió llamarlo a él. Ya en la visita, una vez me trató de basura y yo igual lo saqué a la domiciliaria. 
En el relato de Juana, conocer a una persona detenida y entablar una relación afectiva no resulta extraño para ninguno de los implicados. Ni para el que "estuvo preso toda la vida y tenía chicas que iban", ni para ella que cuando quiere conocer a alguien "le dan teléfonos" de personas detenidas.

Para Juana, haberlo "sacado a la domiciliaria" implica haber asumido una responsabilidad de la que no puede desligarse. En ocasiones, manifestó tener deseos de dejar de vivir con su marido pero que no puede hacerlo porque la dueña de la vivienda solo quiere alquilarle a ella. En otra oportunidad, señaló que querría dejarlo pero que suponía que dejarlo implicaba asumir la responsabilidad de que él vuelva a la cárcel.

Muchas compañeras le señalaron a Juana que su marido debía tratarla con respeto y que ella no podía "convertir la casa en una cárcel” para que él estuviera tranquilo. Incluso cuando Juana escuchaba estas palabras de apoyo decía sentirse tranquila puesto que ella ya le había avisado antes de casarse - que a ella le gustaba salir de la casa y visitar a los vecinos del barrio.

Sin embargo, es interesante notar que en estas reuniones Juana recibe el apoyo de otras mujeres familiares e incluso el consejo explícito que le recomienda dejar a su marido, mientras que abogadas militantes por los derechos de los detenidos le recuerdan la responsabilidad que ella tiene ante el juez por la libertad del detenido. Es solo a partir de la presión que ejercen algunas señalando que la libertad de Juana no es menos importante que la de su marido, que las abogadas dejan de intervenir en la protección de ese derecho del condenado.

Asimismo, Juana señala que está esperando un "hecho de violencia” para dejar a su marido. Nuevamente, las abogadas le explican qué pasos debería seguir en ese caso. Sin embargo, otra compañera pregunta cómo es la convivencia y así Juana comenta que él la agrede verbalmente, que no quiere que salga y que con el propósito de impedir su salida la amenaza. Las primeras veces, le decía que él saldría provocando una violación a su arresto y corriendo el riesgo de ser detenido. Pero como esta amenaza no resultaba efectiva, comenzó a amenazarla con tirar toda su ropa. En otras ocasiones la dejaba encerrada para que no pudiera salir o cerraba la puerta de modo tal que ella no pudiera volver a entrar. También contó que en una oportunidad le tiró una escoba, pero tuvo mala puntería y no la golpeó. Desde la perspectiva de Juana estos no son hechos de violencia.

En este sentido, nos parece importante destacar que las violencias, los feminismos y los punitivismos tienen vinculaciones impensadas y no lineales. La cárcel o una condena no interrumpe la violencia que sufren las mujeres, así como también supone nuevas formas de violencia como en el caso de Juana que termina padeciendo las consecuencias del castigo por un delito que ella no cometió.

\section{Comentarios finales}

Para finalizar, este trabajo puede dar cuenta de algunos de los daños que la prisión produce en la Argentina, evidenciando que estos no alcanzan exclusivamente a los detenidos. Las experiencias 
de todos los sujetos que se vinculan con ella, incluyendo a quienes integran las redes de afecto circundantes a la prisión, son amplias y diversas. Sin embargo, este trabajo de campo muestra que la dispersión geográfica de los penales del sistema federal y la diversidad de condiciones de detención en ese sistema y en las cárceles de la provincia de Buenos Aires no implican que cada detenido y sus familiares vivan experiencias incomparable con las de otros. Antes bien, la circulación y rotación de los detenidos es permanente, asimismo la rotación de las familiares que acompañan lo es, ya sea por la rotación del detenido o porque acompañan a más de un detenido a lo largo de sus vidas.

En este sentido, como las experiencias carcelarias se extienden en los barrios populares - merced al expansionismo carcelario y a la selectividad del sistema penal - las experiencias de las mujeres familiares que pretendemos retratar son una de las trayectorias posibles (y frecuentes) para las mujeres de lose sectores populares.

Se trata de un tema a todas luces significativo dado que merced al encarcelamiento extendido, la situación de acompañar a familiares detenidos alcanza en algún momento de sus vidas a una enorme porción de las mujeres de los sectores populares de Buenos Aires. Incluso, el trabajo de campo realizado muestra que muchas de ellas son socializadas desde pequeñas en esta labor yendo a la cárcel junto a sus madres a visitar padres o tíos. De este modo, estas tareas se naturalizan. En un sentido similar, la asistencia a la visita ha implicado para algunas mujeres conocer a otros detenidos de quienes terminaron siendo parejas. La visita es entonces uno de los espacios de sociabilidad importante en las vidas de buena parte de los sectores populares.

La confluencia de algunas mujeres en la asociación de familiares y las conversaciones y seguimientos posteriores realizados a lo largo de estos años pueden dar testimonio de la construcción de un conocimiento situado que tiene algo para contar tanto respecto de los múltiples daños que produce la cárcel generando formas de confinamiento que van más allá de la prisión como también sobre la diversidad de experiencias de sujeción de atraviesan las mujeres. Dar cuenta de la superposición y solapamiento de estas formas es un tarea necesaria para las reivindicaciones feministas. En este sentido, este trabajo pretende contribuir a la reposición de experiencias de mujeres pobres en las que interactúan al mismo tiempo distintas formas de desigualdades sociales. Así, en la intersección de las violencias institucionales, las violencias de genero, las desigualdades socioeconómicas se actualizan y se reproducen formas de subordinación que afectan especialmente a las mujeres de los sectores populares.

También es interesante señalar, que la asociación de familiares es ejemplo de la construcción de un movimiento y conocimiento colectivo. La forma de trabajo y de acompañamiento a lo largo de años ha logrado dar cuenta no solo del sufrimiento del detenido, sino también de las mujeres en su rol de acompañar. En este sentido, para muchas mujeres la participación en esta asociación ha permitido reafirmar aprendizajes individuales y ganar confianza y relaciones de solidaridad que convierten la experiencia de ser familiar de un detenido en un evento más tolerable. Así, frente a las narrativas de competencia entre mujeres que parecen proponer 
detenidos y el servicio penitenciario, quienes se nuclean en la asociación han sabido encontrar un espacio de contención y reconocimiento. En el extremo, parece haber una reivindicación que una vez escuche decir a la presidenta de la asociación: "Ya hablamos 10 años de ellos, nos toca 10 años de hablar de nosotras".

\section{Referencias}

Barbosa, A. (2006). O baile e a prisão: onde se juntam as pontas dos segmentos locais que respondem pela dinâmica do tráfico de drogas no Rio de Janeiro. Cadernos de Ciências Humanas - Especiaria, 9(15), 119-135.

Comfort, M. (2008). Doing time together. Love and family in the shadow of the psison. The University of Chicago Press

Comfort, M. (2011). En el Tubo de San Quintín: la “prisionización secundaria” de las mujeres que visitan a los reclusos. Cuadernos del GESPYDH, 1, 23-39.

Corazza Padovani, N. (2015). Sobre casos e casamentos: afetos e amores através de penitenciárias femininas em Sao Paulo e Barcelona (Tesis doctoral) Universidade Estadual de Campinas, Brasil.

Delphy, C. (2013). L'ennemi pri ncipal. Économie politique du patriarcat. Syllepse.

Faur, E., y Pereyra F. (2018) Gramáticas del cuidado. En J. Piovani y A. Salvia (eds). La Argentina en el siglo XXI. Cómo somos, vivimos y convivimos en una sociedad desigual (pp. 497-535). Siglo XXI

Ferreccio, V. (2017). La larga sombra de la prisión. Una etnografía de los efectos extendidos del encarcelamiento. Paidós.

Godoi, R. (2016) Intimacy and power: body searches and intimate visits in the prison system of São Paulo, Brazil. Champ Penal. 13, https://doi.org/10.4000/champpenal.9386

Jelin, E. (2012) La familia en Argentina. Trayectorias históricas y realidades contemporáneas. En V. Esquivel, L. Faur y E. Jelin (eds.), Las lógicas del cuidado infantil. IDES.

Mancini, I. (2019). Medios de comunicación y formas de sociabilidad en circuitos carcelarios de la Argentina. Revista Sociedad, 39, 145-159. https://publicaciones.sociales.uba.ar/index.php/revistasociedad/ article/view/5094

Mancini, I. (2020). Las luchas contra el delito y sus efectos en la Argentina. Sobre la expansión del encarcelamiento y las dificultades de seguir a nuestros presos. Revista CS, (31), 139-158. https://doi. org/10.18046/recs.i31.3717

Marcus, G. (2001). Etnografía en/del sistema mundo. El surgimiento de la etnografía multilocal. Alteridades, 11(22), 111-127. https://alteridades.izt.uam.mx/index.php/Alte/article/view/388

Oleastro, I. (2019) Derecho a sentir. Etnografías contemporáneas, 5(8), 123-140. https://revistasacademicas. unsam.edu.ar/index.php/etnocontemp/article/view/486

Sciortino, S (2012) La etnografía en la construcción de una perspectiva de género situada. Clepsydra, 11, 41-58. https://www.ull.es/revistas/index.php/clepsydra/article/view/2533

Stolke, V (2014) ¿Qué tiene que ver el género con el parentesco? Cuadernos de Pesquisa, 44(151), 176-189. http://dx.doi.org/10.1590/198053142848 
Sykes, G. (2017). La sociedad de los cautivos. Estudio de una cárcel de máxima seguridad. Siglo XXI.

Vazquez Laba, V. (2019). Feminismos, género y transgénero. Breve historia desde el siglo XIX hasta nuestros días. Unsam Edita.

Telles, V. (2011). Ilegalismos populares e relações de poder nas tramas da cidade. En R. Cabanes, I. Georges, C. Rizek, y V. Telles (Orgs.). Saídas de Emergência: Ganhar/Perder a vida na periferia de São Paulo. (pp 155-167). Boitempo.

\section{AUTORA}

Ines Mancini. Doctora en Antropología Social por la Universidad Nacional de San Martín Magister en Antropología Social y política por FLACSO, Argentina. Investigadora Adjunta de CONICET. Profesora Adjunta de Escuela IDAES, Universidad Nacional de San Martín. 